\title{
Effects of genistein on anti-tumor activity of cisplatin in human cervical cancer cell lines
}

\author{
Hyunju Liu', Garam Lee', Jung In Lee ${ }^{2}$, Tae-Gyu Ahn', Soo Ah Kim \\ Departments of ${ }^{1}$ Obstetrics and Gynecology, ${ }^{2}$ Internal Medicine, College of Medicine, Chosun University, Gwangju, Korea
}

\section{Objective}

To investigate the effect of genistein on the anticancer effects of chemotherapeutic agents, we examined the effect of a genistein and cisplatin combination on CaSki human cervical cancer cells.

\section{Methods}

After the cervical cancer cells (HeLa cells, CaSki cells) had been cultured, cisplatin and genistein were added to the culture medium, and the cell activity was measured using MTT assay. The CaSki cells were cultured in a medium containing cisplatin and genistein, and then, the cells were collected in order to measure p53, Bcl2, ERK, and caspase 3 levels by western blotting.

Results

Both the HeLa and CaSki cells had decreased cell viabilities when the cisplatin concentration was $10 \mu \mathrm{M}$ or higher. When combined with genistein, the cell viabilities of the HeLa and CaSki cells decreased at cisplatin concentrations of $8 \mu \mathrm{M}$ and $6 \mu \mathrm{M}$, respectively. The administration of genistein increased the toxicity of cisplatin in the HeLa and CaSki cells. In the CaSki cells, the p-ERK1/2 level decreased by 37\%, the p53 expression level increased by 304\%, and the cleaved caspase 3 level increased by $115 \%$ in the cisplatin+genistein group compared to that in the cisplatin group. $\mathrm{Bcl} 2$ expression was reduced by $69 \%$ in the cisplatin+genistein group compared to that in the cisplatin group.

\section{Conclusion}

Genistein enhances the anticancer effect of cisplatin in CaSki cells, and can be used as a chemotherapeutic adjuvant to increase the activity of a chemotherapeutic agent.

Keywords: Genistein; Cisplatin; CaSki cell; HeLa cell

\section{Introduction}

According to the statistics for 2018, cervical cancer is the fourth most common cancer in women worldwide, with 569,847 patients yearly [1]. Patients with cervical cancer who have progressed to an inoperable stage or have experienced recurrence receive widely used anti-cancer chemotherapy and platinum-based chemotherapy [2]. Cisplatin is a platinum-based chemotherapeutic agent that is widely used for the treatment of malignant tumors, such as cervical cancer, lung cancer, and ovarian cancer [3]. Cisplatin mainly induces cross-linking at the N7-position of guanosine, which modifies DNA to induce apoptosis and kill cancer cells [4]. However, the use of cisplatin as a cancer treatment has been limited owing to its serious side effects involving the kidney or hearing impairment and the emergence of resistant cancer cells [5]. In order to overcome anti-cancer drug resistance, high-dose chemotherapy with increasing dose combination therapy that combines several chemotherapy agents, and

Received: 2019.03.16. Revised: 2019.05.28. Accepted: 2019.06.04. Corresponding author: Soo Ah Kim

Department of Obstetrics and Gynecology, College of Medicine, Chosun University, 309 Pilmun-daero, Dong-gu, Gwangju 61452, Korea

E-mail: ksa@chosun.ac.kr

https://orcid.org/0000-0002-9049-1741

Articles published in Obstet Gynecol Sci are open-access, distributed under the terms of the Creative Commons Attribution Non-Commercial License (http://creativecommons. org/licenses/by-nc/3.0/) which permits unrestricted non-commercial use, distribution, and reproduction in any medium, provided the original work is properly cited.

Copyright $\odot 2019$ Korean Society of Obstetrics and Gynecology 


\section{Obstetrics \& Gynecology Science}

Hyunju Liu, et al. Effects of genistein on cisplatin

concurrent therapy that also involves other therapies like radiotherapy, have been attempted $[6,7]$. High-dose therapy increases the anti-cancer effect, but the side effects of the chemotherapeutic agent are also increased at the same time, which is a problem for general use. Therefore, the development of a chemotherapy adjuvant that can increase the anticancer activity of chemotherapeutic agents, or reduce the toxic side effects of anti-cancer drugs, is recognized as an important research task in the field of cancer therapy, along with the development of chemotherapeutic agents. Recently, polyphenols with physiological activity derived from natural materials for the treatment and prevention of various diseases have been attracting attention [8].

Abundant in beans and plants, genistein (4',5,7-trihydroxyisoflavone) is a polyphenolic substance that is known to be a phytoestrogen because it acts on estrogen receptors [9]. Genistein is known to inhibit the proliferation of human gastric cancer cells [10], human colorectal adenocarcinoma cells [11], and cervical cancer cells [12]. It is also known to inhibit the development of cancer by acting on antioxidant activity, and inhibiting carcinogen-activating enzymes, cell receptors, and signal transduction [9].

It has been reported that the combination of genistein and cisplatin increases anticancer activity against various cancer cells, such as lung cancer [13], ovarian cancer [14], and breast cancer cell lines [15]. In addition, it has been reported that genistein enhances the anticancer activity of cisplatin against cervical cancer cells [16]. However, most of these experiments have involved HeLa cells, and there is no report on the use of CaSki cells.

The objectives of the present study were to investigate the effect of genistein on the antitumor activity of cisplatin using CaSki cells, and to determine the mechanism of action of genistein against cisplatin, p53, Bcl2, ERK, and caspase 3.

\section{Materials and methods}

\section{Cell culture}

The cervical cancer cells (HeLa and CaSki cells) used in the present experiment were purchased from the American Type Culture Collection. Mouse breast cancer cells were cultured in Dulbecco's modified Eagle's medium (DMEM)-high glucose medium (Gibco BRL, Grand Island, NY, USA) containing 10\% fetal bovine serum, streptomycin $(100 \mathrm{U} / \mathrm{mL})$, and penicillin
$(100 \mathrm{U} / \mathrm{mL})$ at $37^{\circ} \mathrm{C}$ in $5 \% \mathrm{CO}_{2}$.

\section{Cell viability measurement}

The cisplatin and genistein used in the experiment were purchased from Sigma Chemical Co. (St. Louis, MO, USA). The cisplatin and genistein were dissolved in dimethyl sulfoxide and diluted with phosphate-buffered saline before they were added to the culture medium. The experimental groups were divided into 4 groups: a control (C) group, a cisplatin (CP) group, a genistein $(\mathrm{G})$ group, and a cisplatin+genistein $(\mathrm{CP}+\mathrm{G})$ group. We added $2 \times 10^{4}$ HeLa or CaSki cells in culture medium to each well of a 96-well plate, and cultured them for 24 hours. After adding genistein $(0-180 \mu \mathrm{M})$ and cisplatin $(0-14 \mu \mathrm{M})$, the cells were cultured for another 24 hours. Then, cell viability was determined using a 3-(4,5-dimethylthiazol-2-yl)-2,5-diphenyltetrazolium bromide (MTT) assay [17]. The absorbance of 3 wells was measured for each group, and the mean value was calculated. The experiment was repeated 3 times in such a way. Cell viability was calculated from the measured absorbance using the following equation and expressed as relative viability:

$$
\text { Relative viability }=\frac{\text { Absorbance in test group }}{\text { Absorbance in control group }} \times 100
$$

\section{Western blotting}

The CaSki cells were divided into a C group, a CP group, and a $\mathrm{CP}+\mathrm{G}$ group. For the $\mathrm{CP}$ group, $6 \mu \mathrm{M}$ cisplatin was added to the culture medium, while $6 \mu \mathrm{M}$ cisplatin and $80 \mu \mathrm{M}$ genistein were added to the culture medium of the $\mathrm{CP}+\mathrm{P}$ group. The cells were cultured for 24 hours and then collected. We was added $0.3 \mathrm{~mL}$ of lysis buffer $(50 \mathrm{mM}$ Tris $\mathrm{pH} 7.4,150 \mathrm{mM} \mathrm{NaCl}, 1 \%$ Triton X-100, 1\% NP-40, 0.1\% sodium dodecyl sulfate [SDS]) containing $1 \mathrm{mM}$ protease inhibitor (PMSF) to the collected cells. After homogenization using a Teflon homogenizer (BioMasher, Tokyo, Japan), centrifugation was performed at 12,000 rpm for 10 minutes, and the supernatant was collected and used as a sample.

The proteins in the collected supernatant were quantitated using a Bradford protein assay kit (Bio-Rad, Hercules, CA, USA), and the same amount of protein was electrophoresed by sodium dodecyl sulfate-polyacrylamide gel electrophoresis (10\% SDS). The proteins were then transferred to a polyvinylidene fluoride (PVDF) membrane. The protein-transferred PVDF membranes were treated with blocking buffer ( $5 \%$ 


\title{
Obstetrics \& Gynecology Science
}

\author{
Vol. 62, No. 5, 2019
}

skim milk), and incubated with primary antibodies (anticaspase $3 \mathrm{Ab}$, anti-p53 Ab, anti-Bcl2 Ab, anti-ERK1/-ERK1/2 Ab, anti- $\beta$-actin Ab; Santa Cruz Biotechnology, Santa Cruz, CA, USA) and a secondary antibody (horseradish peroxidaseconjugated Ab; Santa Cruz Biotechnology). The protein bands were detected using an enhanced chemiluminescence kit (BioNote, Hwaseong, Korea), analyzed using Image Lab 5.1 software (Bio-Rad), and expressed as the concentration relative to that of $\beta$-actin.

\section{Analysis of experimental results}

Each measurement is expressed as the mean \pm standard deviation, and the results were analyzed by one-way analysis of variance using SPSS 12.0 software (SPSS Inc., Chicago, IL, USA). The significance of the differences was evaluated at the $P<0.05$ using Duncan's multiple range test.

\section{Results}

\section{Effect of cisplatin on cervical cancer cell viability}

The effect of cisplatin on the viabilities of HeLa and CaSki cells is shown in Table 1.

The viability of HeLa cells decreased at a concentration of $10 \mu \mathrm{M}$ or more, and the viability of CaSki cells decreased at $8 \mu \mathrm{M}$ or more. The cisplatin-induced decrease in cell viability

Table 1. Effects of cisplatin on the viability of cervical cancer cells

\begin{tabular}{lrr}
\hline \multirow{2}{*}{$\begin{array}{c}\text { Cisplatin } \\
\text { concentration }(\boldsymbol{\mu M})\end{array}$} & \multicolumn{2}{c}{ Relative vitality (\%) } \\
\cline { 2 - 3 } 0 & $100.1 \pm 7.3^{\mathrm{d}}$ & $100.3 \pm 7.1^{\mathrm{d}}$ \\
1 & $101.5 \pm 9.2^{\mathrm{d}}$ & $100.2 \pm 9.5^{\mathrm{d}}$ \\
2 & $97.9 \pm 7.9^{\mathrm{d}}$ & $98.4 \pm 8.9^{\mathrm{d}}$ \\
4 & $101.2 \pm 8.9^{\mathrm{d}}$ & $102.8 \pm 9.2^{\mathrm{d}}$ \\
6 & $98.2 \pm 7.8^{\mathrm{d}}$ & $98.9 \pm 7.4^{\mathrm{d}}$ \\
8 & $98.0 \pm 9.3^{\mathrm{d}}$ & $81.2 \pm 7.0^{\mathrm{c}}$ \\
10 & $75.8 \pm 7.1^{\mathrm{c}}$ & $41.4 \pm 4.3^{\mathrm{b}}$ \\
12 & $35.3 \pm 4.2^{\mathrm{b}}$ & $15.1 \pm 4.2^{\mathrm{a}}$ \\
14 & $14.7 \pm 3.3^{\mathrm{a}}$ & $13.1 \pm 3.1^{\mathrm{a}}$ \\
\hline
\end{tabular}

Relative vitality $(\%)=($ Absorbance in test group/Absorbance in control group) $\times 100$, which is an indication of cell viability. Representative results are shown as the mean \pm standard deviation of triplicates. Values with different superscripts in the same column are significantly different $(P<0.05)$ was greater in the CaSki cells, indicating that CaSki cells are more susceptible to cisplatin than HeLa cells.

\section{Effect of genistein on cervical cancer cell viability}

The effect of genistein on the viabilities of the HeLa and CaSki cells is shown in Table 2.

When measured using the MTT assay, viability decreased at a genistein concentration of $120 \mu \mathrm{M}$ or more in both the HeLa and CaSki cells, and the degree to which cell viability decreased was higher in the HeLa cells than that in the CaSki cells.

\section{Effect of combination of cisplatin and genistein on cervical cancer cell viability}

The effect of the combination of cisplatin and genistein on the viabilities of the CaSki and HeLa cells is shown in Fig. 1.

In the CaSki cells, the cytotoxicity of cisplatin was increased by the administration of genistein; cell viability was decreased at cisplatin concentrations of $10 \mu \mathrm{M}$ or more in the control group without genistein, whereas there was a decrease in cell viability in the group with genistein at cisplatin concentrations of $6 \mu \mathrm{M}$ or more.

In the HeLa cells, the cytotoxicity of cisplatin was increased by the administration of genistein; cell viability was decreased at cisplatin concentrations of $10 \mu \mathrm{M}$ or more in the control group without genistein, whereas there was a decrease in cell viability in the group with genistein at cisplatin concentrations of $8 \mu \mathrm{M}$ or more.

Table 2. Effects of genistein on the viability of cervical cancer cells

\begin{tabular}{lcr}
\hline \multirow{2}{*}{$\begin{array}{c}\text { Genistein concentra- } \\
\text { tion }(\boldsymbol{\mu M})\end{array}$} & \multicolumn{2}{c}{ Relative vitality $(\%)$} \\
\cline { 2 - 3 } & HeLa cell & CaSki cell \\
\hline 0 & $100.7 \pm 8.6^{\mathrm{d}}$ & $100.1 \pm 6.7^{\mathrm{d}}$ \\
40 & $103.1 \pm 9.4^{\mathrm{d}}$ & $101.2 \pm 8.4^{\mathrm{d}}$ \\
60 & $102.4 \pm 8.0^{\mathrm{d}}$ & $98.9 \pm 8.4^{\mathrm{d}}$ \\
80 & $101.7 \pm 8.5^{\mathrm{d}}$ & $102.1 \pm 7.8^{\mathrm{d}}$ \\
100 & $98.1 \pm 7.2^{\mathrm{d}}$ & $99.5 \pm 7.2^{\mathrm{d}}$ \\
120 & $81.4 \pm 9.0^{\mathrm{c}}$ & $92.1 \pm 7.7^{\mathrm{d}}$ \\
140 & $55.7 \pm 7.6^{\mathrm{b}}$ & $78.3 \pm 5.4^{\mathrm{c}}$ \\
160 & $19.6 \pm 4.1^{\mathrm{a}}$ & $37.7 \pm 4.3^{\mathrm{b}}$ \\
180 & $14.5 \pm 3.2^{\mathrm{a}}$ & $13.4 \pm 3.1^{\mathrm{a}}$ \\
\hline
\end{tabular}

Representative results are shown as the mean \pm standard deviation of triplicates. Values with different superscripts in the same column are significantly different $(P<0.05)$. 


\section{Obstetrics \& Gynecology Science}

Hyunju Liu, et al. Effects of genistein on cisplatin

\section{Effect of combined administration of cisplatin and genistein on p53, ERK1/2, caspase 3, and Bcl2 levels in CaSki cells}

The effect of the combined administration of cisplatin and genistein on the expression of genes involved in apoptosis in the CaSki cells is shown in Fig. 2.

The expression level of apoptosis-related proteins was assayed by western blotting using the comparative concentration of $\beta$-actin.

The expression of ERK1/2 in the CaSki cells did not differ
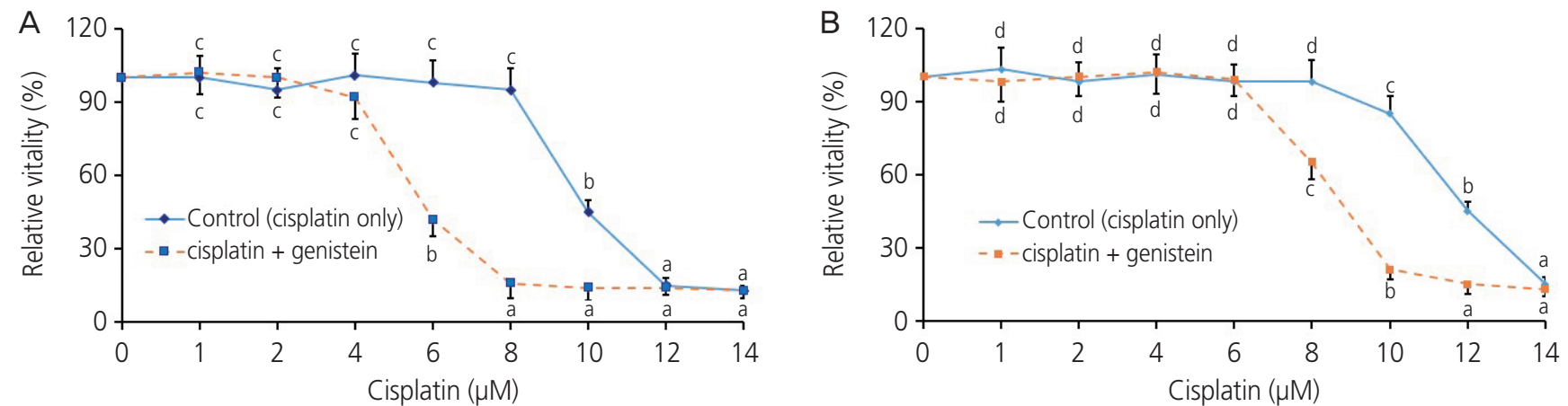

Fig. 1. (A) Effects of genistein on cisplatin-induced cytotoxicity of CaSki cells. CaSki cells viability examined by 3-(4,5-dimethylthiazol2-yl)-2,5-diphenyltetrazolium bromide assay. Representative results are shown as the mean \pm standard deviation (SD) of triplicates. Values with same superscripts are not significantly different $(P<0.05)$. (B) Effects of genistein on cisplatin-induced cytotoxicity of HeLa cells. Representative results are shown as the mean \pm SD of triplicates. Values with same superscripts are not significantly different $(P<0.05)$.

A

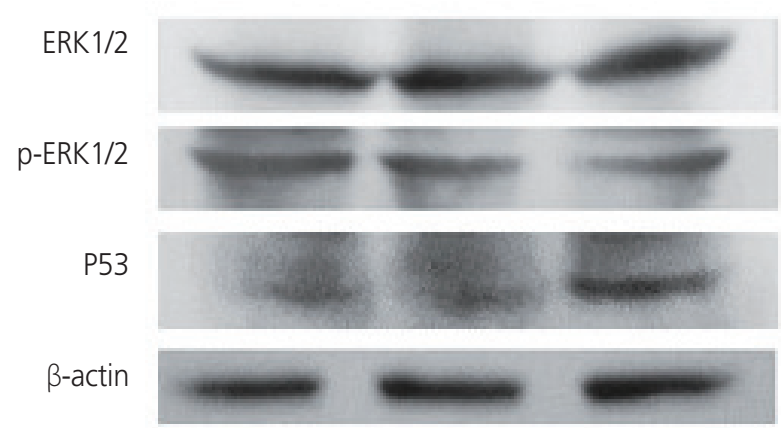

B

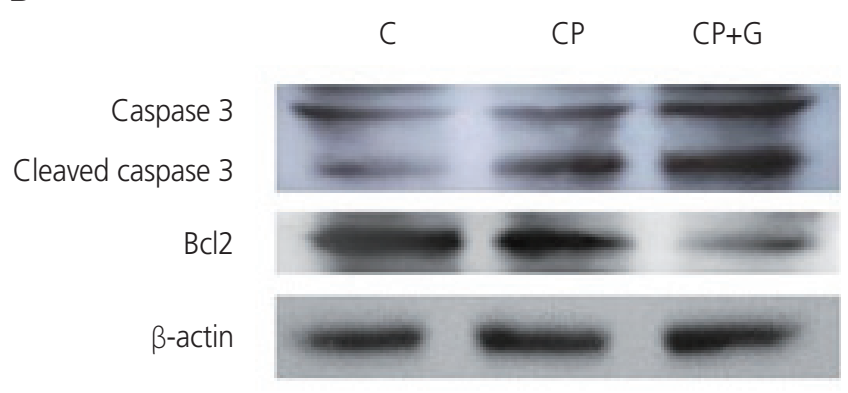

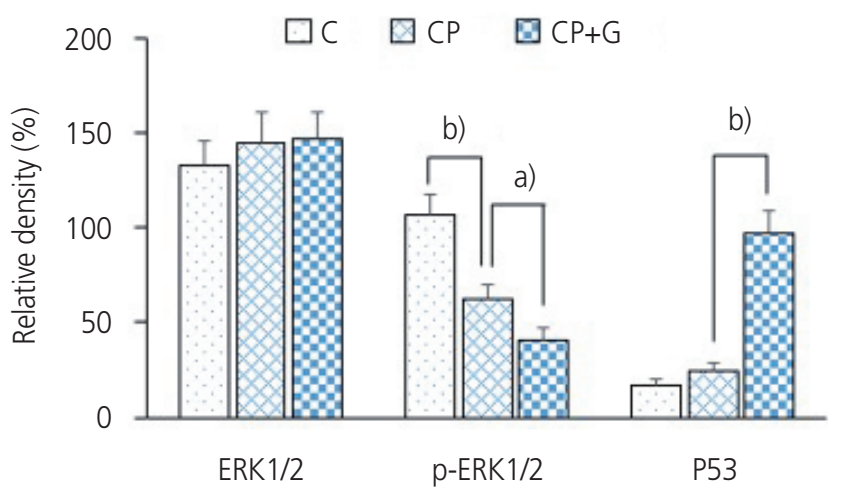

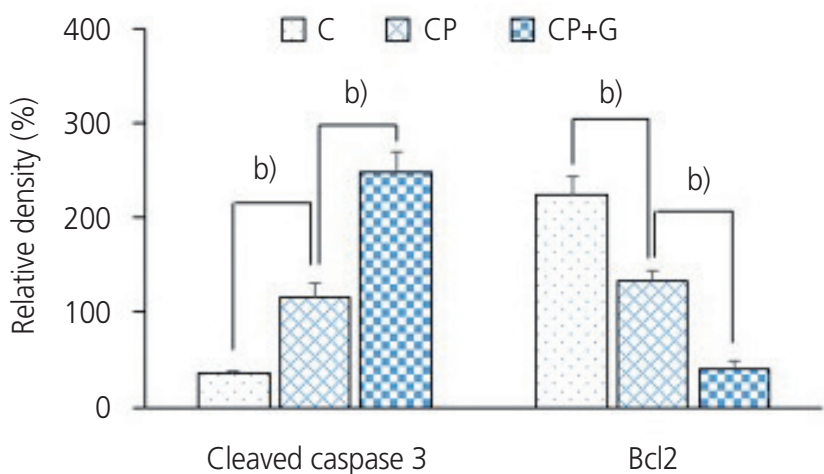

Fig. 2. (A) Effects of cisplatin and genistein on levels of ERK1/2, p-ERK1/2 and P53 in CaSki cells. Representative results are shown as the mean \pm standard deviation (SD) of triplicates. (B) Effects of cisplatin and genistein on levels of caspase 3 and $B c 12$ in CaSki cells. Representative results are shown as the mean \pm SD of triplicates. ${ }^{a} P<0.05,{ }^{\text {b) }} P<0.01$ indicate significant differences compared to the corresponding counterparts. $C$, control; $C P$, cisplatin; $C P+G$, cisplatin+genistein. 


\title{
Obstetrics \& Gynecology Science
}

\author{
Vol. 62, No. 5, 2019
}

significantly among the control, $C P$, and $C P+G$ groups. The quantity of $\mathrm{p}$-ERK $1 / 2$ was decreased by $32 \%$ in the CP group compared to that in the control group, and by $37 \%$ in the $\mathrm{CP}+\mathrm{G}$ group compared to that in the $\mathrm{CP}$ group.

The expression of p53 in the CaSki cells was increased by $41 \%$ in the CP group compared to the control group, and by $304 \%$ in the $C P+G$ group compared to that in the CP group.

The expression of cleaved caspase 3 in the CaSki cells was increased by $228 \%$ in the CP group compared to that in the control group, and by $115 \%$ in the $\mathrm{CP}+\mathrm{G}$ group compared to that in the CP group.

The expression of $\mathrm{BCl} 2$ in the CaSki cells was decreased by $40 \%$ in the CP group compared to that in the control group, and by $69 \%$ in the $C P+G$ group compared to that in the $C P$ group.

\section{Discussion}

In the present experiment, the effect of genistein on the anti-tumor activity of cisplatin was investigated using human cervical cancer cell lines (HeLa and CaSki cells). Genistein increased the sensitivity of cancer cells to cisplatin. The CaSki cells showed a decrease in cell viability at a cisplatin concentration of $10 \mu \mathrm{M}$ or higher. However, when combined with $80 \mu \mathrm{M}$ genistein, there was a decrease in cell viability at a cisplatin concentration of $6 \mu \mathrm{M}$ or higher, indicating that genistein increased the cytotoxicity of cisplatin in the CaSki cells. The response to cisplatin and genistein of the HeLa cells was similar to that of the CaSki cells, suggesting that genistein may increase the sensitivity of cervical cancer cells to cisplatin. Similar results have been reported from other studies, with the combination of genistein and cisplatin showing increased anti-cancer effect in the lung cancer cell study by Tokalov et al. [13], in the human ovarian tumor cell study by Arzuman et al. [14], and in the breast cancer cell study by Pons et al. [15]. In addition, Sahin et al. [16] reported that genistein inhibited the NF-kB and Akt/mTOR pathways in HeLa cells, which enhanced the anticancer activity of cisplatin. The NF-kB and Akt/mTOR pathways are associated with cell growth and survival.

Apoptosis is the mechanism of programed cell death, and is known to be closely related to the growth of cancer cells and the mechanism of action of anti-cancer drugs. ERK1/2, $\mathrm{BCl} 2, \mathrm{p} 53$, and caspase 3 are involved in controlling apop- tosis; ERK1/2 and Bcl2 inhibit apoptosis, whereas p53 and caspase 3 promote apoptosis [18].

In the present study, genistein and cisplatin did not affect ERK1/2 expression; however, the quantity of $p$-ERK $1 / 2$ was reduced, which appeared to inhibit ERK1/2 phosphorylation. ERK $1 / 2$ is activated by $p$-ERK $1 / 2$, and promotes the proliferation of cancer cells. Kielbik et al. [19] showed that when cisplatin was administered to ovarian cancer cells, ERK1/2 activation increased in cisplatin-resistant cells, there was reduced ERK1/2 activation in cisplatin-sensitive cells, and the inhibitor of ERK $1 / 2$ activation increased cisplatin sensitivity in resistant cells. In the present experiment, the increase in cytotoxicity in the CaSki cells of the $C P+G$ group is presumed to have been closely related to the decrease in $p$-ERK $1 / 2$ levels in that group.

Yang et al. [20] reported that the treatment of cisplatin-resistant cervical cancer cells with microRNAs reduced $\mathrm{BCl} 2$ expression, and converted cisplatin-resistant cells into cisplatinsensitive cells. In the present study, Bcl2 levels were reduced in the CaSki cells of the $C P+G$ group, which is thought to have been related to increased cytotoxicity in the $\mathrm{CP}+\mathrm{G}$ group. p-ERK1/2 is known to promote $\mathrm{BCl} 2$ induction [21]. In the present study, the $p$-ERK $1 / 2$ and $B c 12$ levels were reduced in the $\mathrm{CP}+\mathrm{G}$ group compared to those in the cisplatin group, indicating that genistein inhibited the phosphorylation of ERK $1 / 2$ and induced the decrease in the level of $B C l 2$. $\mathrm{BC} 2 \mathrm{2}$ is an anti-apoptotic protein that inhibits apoptosis. The decrease in the level of $\mathrm{BCl} 2$ in the $\mathrm{CP}+\mathrm{G}$ group might have induced apoptosis in the CaSki cells and increased cytotoxicity.

Wei et al. [22] reported that the treatment of cisplatinresistant gastric cancer cells with a type of flavonoid called liquiritin increased p53 expression and converted them to cisplatin-sensitive cells. In the present study, p53 was increased in the CaSki cells of the $C P+G$ group, which may have been related to increased cytotoxicity in the $\mathrm{CP}+\mathrm{G}$ group.

Apoptosis is ultimately caused by the activation of caspase, and caspase 3 is cleaved into cleaved caspase 3 , leading to apoptosis [18]. In the present experiment, the level of cleaved caspase 3 increased in the CaSki cells of the $C P+G$ group, and apoptosis was probably promoted by the increase in the level of cleaved caspase 3.

Based on the results of the experiments described above, the combination of genistein and cisplatin in CaSki cells inhibited ERK1/2 phosphorylation, decreased the level of $\mathrm{BCl}$, 


\section{Obstetrics \& Gynecology Science}

Hyunju Liu, et al. Effects of genistein on cisplatin

and increased the levels of p53 and cleaved caspase 3. As a decrease in the level of $\mathrm{BC} 2$ and an increase in the level of p53 activate caspase 3, thereby inducing apoptosis, it is suggested that the increased cytotoxicity of cisplatin by genistein in CaSki cells is due to the activation of the apoptotic pathway following the inhibition of ERK $1 / 2$ phosphorylation and the increase in the level of p53.

Assessing the results of the present experiments, we conclude that genistein enhances the anticancer effect of cisplatin, which may be used as an adjunct to chemotherapy to increase the activity of the chemotherapeutic agent without increasing its toxic side effects. Further studies are needed to elucidate the mechanism of action of genistein in cisplatin anticancer activity.

\section{Acknowledgements}

This study was supported by research fund from Chosun University, 2016.

\section{Conflict of interest}

No potential conflict of interest relevant to this article was reported.

\section{References}

1. Bray F, Ferlay J, Soerjomataram I, Siegel RL, Torre LA, Jemal A. Global cancer statistics 2018: GLOBOCAN estimates of incidence and mortality worldwide for 36 cancers in 185 countries. CA Cancer J Clin 2018;68:394424.

2. Kumar L, Harish P, Malik PS, Khurana S. Chemotherapy and targeted therapy in the management of cervical cancer. Curr Probl Cancer 2018;42:120-8.

3. Dasari S, Tchounwou PB. Cisplatin in cancer therapy: molecular mechanisms of action. Eur J Pharmacol 2014;740:364-78.

4. Wang D, Lippard SJ. Cellular processing of platinum anticancer drugs. Nat Rev Drug Discov 2005;4:307-20.

5. Astolfi L, Ghiselli S, Guaran V, Chicca M, Simoni E, Olivetto $E$, et al. Correlation of adverse effects of cispla- tin administration in patients affected by solid tumours: a retrospective evaluation. Oncol Rep 2013;29:1285-92.

6. Matsuyama R, Reddy S, Smith TJ. Why do patients choose chemotherapy near the end of life? A review of the perspective of those facing death from cancer. J Clin Oncol 2006;24:3490-6.

7. Bartelink H, Schellens JH, Verheij M. The combined use of radiotherapy and chemotherapy in the treatment of solid tumours. Eur J Cancer 2002;38:216-22.

8. Niedzwiecki A, Roomi MW, Kalinovsky T, Rath M. Anticancer efficacy of polyphenols and their combinations. Nutrients 2016;8:552-68.

9. Banerjee S, Li Y, Wang Z, Sarkar FH. Multi-targeted therapy of cancer by genistein. Cancer Lett 2008;269:22642.

10. Zhang Z, Wang CZ, Du GJ, Qi LW, Calway T, He TC, et al. Genistein induces G2/M cell cycle arrest and apoptosis via ATM/p53-dependent pathway in human colon cancer cells. Int J Oncol 2013;43:289-96.

11. Liu YL, Zhang GQ, Yang Y, Zhang CY, Fu RX, Yang YM. Genistein induces G2/M arrest in gastric cancer cells by increasing the tumor suppressor PTEN expression. Nutr Cancer 2013;65:1034-41.

12. Yang YM, Yang Y, Dai WW, Li XM, Ma JQ, Tang LP. Genistein-induced apoptosis is mediated by endoplasmic reticulum stress in cervical cancer cells. Eur Rev Med Pharmacol Sci 2016;20:3292-6.

13. Tokalov SV, Abramyuk AM, Abolmaali ND. Protection of p53 wild type cells from taxol by genistein in the combined treatment of lung cancer. Nutr Cancer 2010;62:795-801.

14. Arzuman L, Beale P, Proschogo N, Yu JQ, Huq F. Combination of genistein and cisplatin with two designed monofunctional platinum agents in human ovarian tumour models. Anticancer Res 2015;35:6027-39.

15. Pons DG, Nadal-Serrano $M$, Torrens-Mas $M$, Oliver J, Roca $P$. The phytoestrogen genistein affects breast cancer cells treatment depending on the ERa/ER $\beta$ ratio. J Cell Biochem 2016;117:218-29.

16. Sahin K, Tuzcu M, Basak N, Caglayan B, Kilic U, Sahin $F$, et al. Sensitization of cervical cancer cells to cisplatin by genistein: the role of NFkB and Akt/mTOR signaling pathways. J Oncol 2012;2012:461562.

17. Sladowski D, Steer SJ, Clothier RH, Balls M. An improved MTT assay. J Immunol Methods 1993;157:203-7. 


\section{Obstetrics \& Gynecology Science}

Vol. 62, No. 5, 2019

18. Fulda S. Targeting apoptosis for anticancer therapy. Semin Cancer Biol 2015;31:84-8.

19. Kielbik M, Krzyzanowski D, Pawlik B, Klink M. Cisplatininduced ERK $1 / 2$ activity promotes $G 1$ to $S$ phase progression which leads to chemoresistance of ovarian cancer cells. Oncotarget 2018;9:19847-60.

20. Yang F, Guo L, Cao Y, Li S, Li J, Liu M. MicroRNA-7-5p promotes cisplatin resistance of cervical cancer cells and modulation of cellular energy homeostasis by regulating the expression of the PARP-1 and BCL2 genes. Med Sci
Monit 2018;24:6506-16.

21. Yang $T$, Xu F, Sheng $Y$, Zhang $W$, Chen $Y$. A targeted proteomics approach to the quantitative analysis of ERK/ $\mathrm{BCl}$-2-mediated anti-apoptosis and multi-drug resistance in breast cancer. Anal Bioanal Chem 2016;408:7491503.

22. Wei F, Jiang X, Gao HY, Gao SH. Liquiritin induces apoptosis and autophagy in cisplatin (DDP)-resistant gastric cancer cells in vitro and xenograft nude mice in vivo. Int J Oncol 2017;51:1383-94. 